\title{
COMMUTER TRAVEL AND SICKNESS ABSENCE OF LONDON OFFICE WORKERS
}

\author{
P. J. TAYLOR* AND S. J. POCOCK \\ TUC Centenary Institute of Occupational Health, London School of Hygiene and Tropical Medicine, Keppel Street, \\ London W.C.1
}

Daily travel to and from work is a characteristic feature of life in all industrialized countries, and with the tendency for more people to live outside the centres of towns and cities the length of the commuter's journey has increased. Nowhere in Britain is this problem more marked than in London where public transport is stretched to the limits of its capacity.

It is a common belief that long and uncomfortable journeys impose a strain upon the commuter which produces fatigue and impairs health. Liepmann (1944) cites many statements in support of this view but noted that objective evidence was scanty and sometimes inconsistent. In a review of the health of London's travelling public, Norman (1959) stated that there was no evidence that those who commuted for two or three hours every day were any less fit than those who 'lived over the shop'. He quoted the study of Williams and Hirch (1950) in support of his statement that travel in buses and underground trains did not increase the spread of infectious disease, but his own studies on sickness rates among bus drivers and conductors could provide only indirect evidence on passengers.

Absence from work due to certified (or uncertified) incapacity is not synonymous with morbidity since many factors, of which ill health is only one, combine to decide whether or not a worker will 'go off sick' (Froggatt, 1970). A recent review of absenteeism states that it increases with the length of the journey (Jones, 1971) but provides no evidence in support. Vernon, Bedford, and Warner (1931) studied miners in six collieries in Scotland, finding some evidence that men with longer journeys had more sickness absence, but there was a closer relationship with voluntary absenteeism. A more elaborate study of 26 coal mines by Buzzard and Liddell (1963) showed only a slight positive association, and when each mine was considered separately the patterns

*Present address and address for reprints:

Post Office Central Headquarters, 23 Howland Street,

London W1P 6 HQ were inconsistent. Liepmann's (1944) studies in the London area failed to show any conclusive association, and Wyatt, Marriott, and Hughes (1943) found higher rates of absence in women only when journeys exceeded one hour in duration. Refinery employees, whose journeys were all less than one hour, showed no evidence of an association (Taylor, 1966).

All these studies, however, measured the journey only in terms of distance or duration, and most used lost time as the only measure of absence. The present investigation was designed to obtain more detailed information about the journeys of office workers in Central London, and to study several factors in relation to both frequency and severity of certified and uncertified sickness absence.

\section{MethodS}

\section{Selection of Sample Population}

To reduce the number of complicating factors we sought a reasonably homogeneous sample of employees in one organization. Several large organizations, unconnected with public transport, were approached. Only two kept comprehensive sickness absence records and one agreed to help when the support of the Unions had been obtained.

The employees worked in three large office blocks, two in the City of London and one nearby in Holborn. All were employed on a five-day week and most started work between 08.30 and 09.00 hours. We defined our sample as office workers under the age of 70 who had been continuously employed in the same building between April 1969 and June 1970. The sample totalled 2,045 persons.

\section{Travel Questionnaire}

A self-administered questionnaire was distributed to all persons in our sample; anonymity was preserved by a 'tear-off' attachment which was removed before the completed forms were returned to us. A serial number on both parts of the form 
enabled subsequent queries to be raised with the personnel department.

A brief introduction explained that the survey was to study problems of commuter journeys and that records of absence due to ill health would also be used. The questionnaire asked for details of the journey to work used most often in the previous 12 months. To facilitate the description, the employee was asked to divide the journey into 'stages', giving times and details of each. A stage was defined as that part of the journey in which neither the method of transport nor the vehicle was changed. Any walk taking more than five minutes was to be included as a separate stage.

For each stage we asked for: the starting time, the type of transport (British Rail train, London Transport train, bus, driver of car, passenger in car, walk, or other means of transport), and the individual's opinion of the stage on a four-point scale (very crowded/congested, crowded/congested, comfortable, fairly empty). For train stages the names of both stations were required, for other stages the two districts.

The employee was asked for the usual total duration of his journey and also to record which of five alternatives most nearly described his opinion of the whole journey: very comfortable, fairly comfortable, neither particularly comfortable nor uncomfortable, fairly uncomfortable, and very uncomfortable.

\section{Objective Assessment of Crowding}

British Rail (BR) and London Transport (LT) agreed to provide us with their own assessments of crowding for as many of the train journeys described in the questionnaire as possible. This was done by their staff without reference to the respondent's own assessment.

For BR journeys we were given the 'loading factors' calculated from the results of a routine survey in October 1969. This factor is defined as the ratio of the number of persons on the train to the number of seats on the train expressed as a percentage. Thus a loading factor of $100 \%$ would mean that the number of passengers was the same as the number of seats. If the loading factor was higher at a station shortly before the terminal this figure was adopted instead of the terminal loading. We obtained such factors for all but 13 of the 1,315 BR journeys.

For LT trains the loading factor was calculated on a somewhat different basis, being the ratio of the average number of passengers to the 'tolerable load' expressed as a percentage, the tolerable load being $2 \cdot 8$ times the seating capacity. The reason for this difference is that about half the floor space of LT underground carriages is designed for standing 8 passengers. These loading factors were assessed at $\frac{3}{8}$ 15 minute intervals and did not refer to specific ? trains as a frequent service operates at peak hours. We obtained loading factors for all but 87 of the $\stackrel{9}{?}$ 1,009 LT train journeys; the others ended at stations for which this information was not available. Unfortunately it was impracticable to obtain loading factors for bus journeys.

Personal Details and Sickness Absence

On the reverse side of the form we were provided $\overrightarrow{0}$ with facts from company records including sex, $\vec{\overrightarrow{ }}$ marital status, grade of job (management, executive, and clerical), and the number of spells and calendar $\frac{\widehat{\alpha}}{\circ}$ days of sickness absence in the 12 months ending $\stackrel{\rho}{子}$ 31 March 1970. Absence was divided into three is categories: uncertified, certified due to influenza, $\stackrel{\sigma}{\omega}$ and certified due to all other causes.

\section{Date Processing and Analysis}

All the information was coded and transferred to punched cards. Subsequent analysis was carried out first using the computer of BR and later that of the University of London.

\section{RESPONSE RATE RESUlts}

We received 1,994 completed questionnaires giving a response rate of $97.5 \%$. Fifty-one persor failed to respond after a second questionnaire, aft but one were male, and their ages and job grades were similar to those of the respondents. Their sickness absence experience was neither unduly high nor unduly low.

\section{Personal Details}

In our sample of 1,994 persons, $1,677(84 \%)$ were male and 317 were female, of whom $185(58 \%)$ were married. In job grade, 266 were management, 1,217 were executive, and 511 were clerical. Most of the women $(80 \%)$ were in the clerical grade. We divided our sample into three age groups by their years of birth; 427 (21\%) were born between 1900 and $1919,918(46 \%)$ between 1920 and 1939, and $649(33 \%)$ since 1940 . These we describe as older, middle aged, and younger employees respectively.

\section{DURATION OF OVER-ALl JoURNEY}

There was a wide range from 12 minutes to $2 \frac{1}{2}$ N hours, with a median duration of one hour. The distribution of travelling time in five-minute intervals $N$ is shown in the Figure. The marked peak at one $\mathrm{C}$ hour is attributable to many giving this time in preference to one within five minutes on either side. Women had somewhat shorter journeys than men, $55 \%$ having journeys of 50 minutes or less whereas this applied to only $32 \%$ of the men. The duration of the journey was not related to age. 


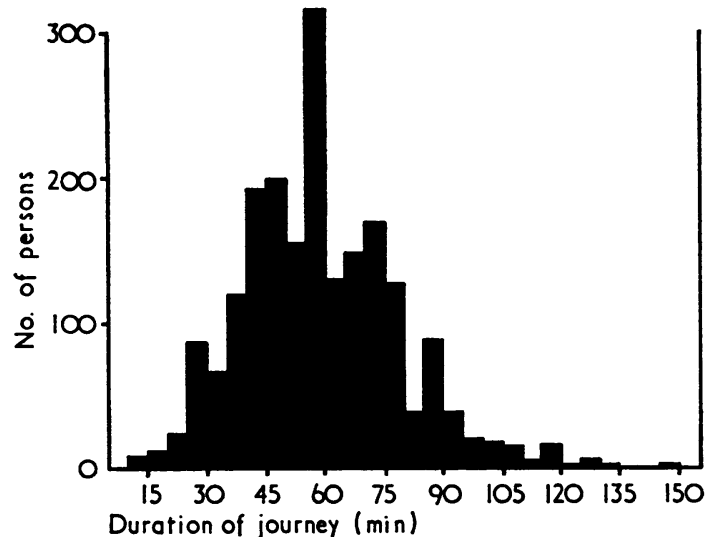

FIGURE-Distribution of travelling time in 5-minute intervals (no. of persons $=1,994)$.

TABLE I

DISTRIBUTIONS OF TOTAL AND PUBLIC TRANSPORT STAGES

\begin{tabular}{c|rr|c|cr}
\hline $\begin{array}{c}\text { Total No. } \\
\text { of Stages }\end{array}$ & $\begin{array}{c}\text { No. of } \\
\text { Persons }\end{array}$ & $(\%)$ & $\begin{array}{c}\text { No. of } \\
\text { Public } \\
\text { Stages }\end{array}$ & $\begin{array}{c}\text { No. of } \\
\text { Persons }\end{array}$ & $(\%)$ \\
\hline 1 & 183 & $(9 \cdot 2)$ & 0 & 104 & $(5 \cdot 2)$ \\
2 & 421 & $(21 \cdot 1)$ & 1 & 846 & $(42 \cdot 4)$ \\
3 & 973 & $(48 \cdot 8)$ & 2 & 795 & $(39 \cdot 9)$ \\
4 & 364 & $(18 \cdot 2)$ & 3 & 223 & $(11 \cdot 2)$ \\
5 or more & 53 & $(2 \cdot 7)$ & 4 or more & 26 & $(1 \cdot 3)$ \\
\hline Total & 1,994 & $(100 \cdot 0)$ & Total & 1,994 & $(100 \cdot 0)$ \\
\hline
\end{tabular}

Number OF Stages. The average number of stages was $2 \cdot 84$, and the distributions of total stages and those involving public transport (Table I) show that the majority of our sample had between two and four stages, with one or two by public transport. Women had slightly fewer stages than men. Although there was a positive association between the over-all duration of the journey and the number of stages, the correlation coefficient of 0.45 indicates that this was not very close.

TyPes OF Transport. One thousand eight hundred and ninety $(94.8 \%)$ of our respondents used some form of public transport for at least one stage of their journey. The largest number of people $(66.0 \%)$ used BR train, $50.7 \%$ used LT train, and $22.8 \%$ travelled by bus. Many people $(40.9 \%)$ used more than one type of public transport in the course of their journey (Table II).

TABLE II

NUMBERS USING TYPES OF PUBLIC TRANSPORT

\begin{tabular}{l|c}
\multicolumn{1}{c|}{ Type of Public Transport } & No. of Persons \\
\hline None & 104 \\
BR train only & 596 \\
LT train only & 408 \\
Bus only & 70 \\
BR train and LT train & 432 \\
BR train and bus & 214 \\
LT train and bus & 96 \\
BR train, LT train and bus & 74 \\
\hline \multicolumn{1}{c}{ Total } & 1,994 \\
\hline
\end{tabular}

A car was used by 412 persons $(20.6 \%)$, and for 88 of these this was the only vehicle. Since 256 also used a BR train and 183 an LT train but only 29 caught a bus, it seems that although the use of a car involved less use of public transport, this is only marked in the case of bus journeys. Moreover, since most used cars only for the first stage the average number of stages at 2.75 was not much less than that for all respondents. On the other hand, car users tended to have longer journeys than the rest. The use of a car decreased with age among the men and only $15 \%$ of women used a car; $80 \%$ of car users drove themselves.

Walking for at least one stage (i.e., for more than 5 minutes) was reported by 1,410 of the respondents and just over a quarter of these had more than one walk as part of their journey to work. However, only 16 people walked all the way to work.

OPINIONS ON COMfORT. The distribution of opinions on the overall comfort of the journey, recorded on the five-point scale, showed that less than one-third considered it as fairly or very uncomfortable (Table III). There was no significant difference between men and women in this, but the proportion of men who considered the journey fairly or very uncomfortable fell with increasing age from $37.5 \%$ in younger men to $30.3 \%$ in the middle-aged and $23.3 \%$ in the older men. Opinion, however, did not relate to the number of stages nor to the total duration of the journey; scoring opinion from one to five, the correlation coefficients were only 0.10 and 0.09 respectively.

Opinions on separate stages allowed us to relate these to the type of transport. LT trains were described as very crowded or crowded by $78 \%$ of those who used them, buses by $54 \%$, and BR trains by $52 \%$. For stages both by car and on foot over $80 \%$ described conditions as comfortable or fairly empty.

Objective Assessment of Train Loading. For BR journeys the median loading factor was in the range $80-89 \%$, and just over one-third of the trains were rated at $100 \%$ or more. For LT trains, using

TABLE III

DISTRIBUTION OF OPINION OF OVERALL COMFORT

\begin{tabular}{l|cc}
\hline \multicolumn{1}{c|}{ Opinion } & \multicolumn{1}{c}{$\begin{array}{c}\text { No. of } \\
\text { Persons }\end{array}$} & $(\%)$ \\
\hline Very comfortable & 67 & $(3 \cdot 4)$ \\
Fairly comfortable & 604 & $(30 \cdot 3)$ \\
Neither particularly comfortable nor & 709 & $(35 \cdot 6)$ \\
uncomfortable & 487 & $(24 \cdot 3)$ \\
Fairly uncomfortable & 127 & $(6 \cdot 4)$ \\
\hline Very uncomfortable & 1,994 & $(100 \cdot 0)$ \\
\hline \multicolumn{1}{c|}{ Total } & & \\
\hline
\end{tabular}


their load factor based on $2 \cdot 8$ persons per seat, the median was in the range of $60-69 \%$, which is approximately equivalent to 1.7 persons per seat.

We compared the individual's assessment of his train journey with the loading factor. For BR trains the median load factors for opinions very crowded, crowded, and comfortable were in the ranges 100-109, 90-99, and $70-79 \%$ respectively. For LT trains the corresponding ranges were $60-69,50-59$, and $40-49 \%$. These trends indicate some degree of association but there was considerable scatter showing substantial variation in opinion. A further reason for this scatter may be the difference between the overall crowding on the train from start to finish of the journey and the situation at the end.

\section{Sickness Absence Rates}

The experience of our sample was fairly typical for office workers. Men had lower rates than women, married women had more than single (Table IV). The total calendar days lost by the sample in the year was $8 \cdot 5$ per person at risk. The usual relationship of absence with age was also found with the frequency of uncertified spells in men falling sharply with increasing age, whereas certified spells for influenza and other causes did not change to any great extent.

Within age groups, the job grade also had a very marked effect on absence rates. The rates among men in the middle-aged group (Table V) show that for all types of absence the rates were highest in the clerical group and lowest among management. Similar differences were observed in other age groups.

\section{The Journey And Sickness Absence}

Personal factors, such as sex, age, and occupational status, must always be taken into account before any attempt can be made to study another factor in relation to sickness absence. Without this, spurious associations can be observed.

TABLE IV

FREQUENCY AND SEVERITY OF SICKNESS ABSENCE BY SEX AND MARITAL STATUS IN YEAR BEGINNING APRIL 1969

\begin{tabular}{|c|c|c|c|c|c|}
\hline & & Male & $\underset{\text { married }}{\text { Un- }}$ & $\begin{array}{c}\text { Married } \\
\text { Female }\end{array}$ & Total \\
\hline & No. of persons & 1,677 & 132 & 185 & 1,994 \\
\hline $\begin{array}{l}\text { Uncertified } \\
\text { Certified 'flu } \\
\begin{array}{c}\text { Other } \\
\text { certified }\end{array}\end{array}$ & $\begin{array}{l}\text { Spells/person } \\
\text { Days/person } \\
\text { Spells/person } \\
\text { Days/person } \\
\text { Spells/person } \\
\text { Days/person }\end{array}$ & $\begin{array}{l}1 \cdot 12 \\
1.65 \\
0.19 \\
1.36 \\
0.37 \\
4.02\end{array}$ & $\begin{array}{l}1 \cdot 89 \\
2.62 \\
0.26 \\
1.56 \\
0.69 \\
7 \cdot 11\end{array}$ & $\begin{array}{l}1.90 \\
2.71 \\
0.28 \\
3.41 \\
1.03 \\
13.38\end{array}$ & $\begin{array}{l}1 \cdot 24 \\
1 \cdot 82 \\
0 \cdot 20 \\
1 \cdot 56 \\
0 \cdot 46 \\
5 \cdot 10\end{array}$ \\
\hline All types & $\begin{array}{l}\text { Spells/person } \\
\text { Days/person }\end{array}$ & $\begin{array}{l}1.68 \\
7.03\end{array}$ & $\begin{array}{r}2 \cdot 84 \\
11 \cdot 29\end{array}$ & $\begin{array}{r}3 \cdot 21 \\
16 \cdot 50\end{array}$ & $\begin{array}{l}1.90 \\
8 \cdot 48\end{array}$ \\
\hline
\end{tabular}

TABLE $\mathbf{V}$

FREQUENCY AND SEVERITY OF SICKNESS ABSENCE IN MIDDLE-AGED MEN BY JOB GRADE

\begin{tabular}{l|l|ccc}
\hline & & $\begin{array}{c}\text { Manage- } \\
\text { ment }\end{array}$ & Executive & Clerical \\
\hline & No. of persons & 153 & 600 & 74 \\
\hline Uncertified & Spells/man & 0.69 & 1.07 & 1.69 \\
Certified 'flu & Days/man & 1.27 & 1.61 & 2.18 \\
Spells/man & 0.16 & 0.21 & 0.30 \\
Certified other & Days/man & 1.08 & 1.52 & 2.57 \\
& Spells/man & 0.28 & 0.35 & 0.87 \\
& Days/man & 2.60 & 4.21 & 7.15 \\
\hline All types & Spells/man & 1.13 & 1.63 & 2.86 \\
& Days/man & 4.95 & 7.34 & 11.90 \\
\hline
\end{tabular}

In this study we allocated employees into 12 strata determined by their sex, age group, marital status (for women), and job grade. We used the technique of indirect standardization which enabled us to allow for these factors when comparing groups of employees classified according to their journeys. Although all previously mentioned aspects of the journey were studied to see whether any association could be found with any of the forms of sickness absence, only those results suggesting a possible relationship are presented.

\section{UNCERTIFIED ABSENCE AND THE JOURNEY}

Since both frequency (spells) and severity (days) are highly skewed in their distribution, it is difficult? to apply formal tests of significance. For this reason we also used the percentage of persons with two or more spells as a third measure of uncertified absence.

In Table VI we present absence rates (standardized for age, sex, and status) for the sample divided into

TABLE VI

UNCERTIFIED ABSENCE AND THE JOURNEY TO WORK (Annual frequency, severity and percentage of persons with two or more spells standardized for age, sex and job grade)

\begin{tabular}{|c|c|c|c|c|}
\hline & $\begin{array}{l}\text { No. of } \\
\text { Persons }\end{array}$ & $\begin{array}{l}\text { Days } \\
\text { Rate }\end{array}$ & $\begin{array}{l}\text { Spells } \\
\text { Rate }\end{array}$ & $\begin{array}{l}\% \text { with } 2+ \\
\text { Spells }\end{array}$ \\
\hline $\begin{array}{l}\text { Private transport } \\
\text { None } \\
\text { Car } \\
\text { Other }\end{array}$ & $\begin{array}{r}1,524 \\
412 \\
58\end{array}$ & $\begin{array}{l}1 \cdot 76 \\
2 \cdot 12 \\
1 \cdot 21\end{array}$ & $\begin{array}{l}1.21 \\
1.41 \\
0.84\end{array}$ & $\begin{array}{l}33 \cdot 0^{*} \\
39 \cdot 2 * \\
23 \cdot 5\end{array}$ \\
\hline $\begin{array}{l}\text { No. of stages } \\
1 \text { or } 2 \\
3 \text { or more } \\
4 \text { or }\end{array}$ & $\begin{array}{l}604 \\
973 \\
417\end{array}$ & $\begin{array}{l}1.69 \\
1.87 \\
1.90\end{array}$ & $\begin{array}{l}1 \cdot 14 \\
1 \cdot 29 \\
1 \cdot 28\end{array}$ & $\left.\begin{array}{l}29 \cdot 9 * * \\
35 \cdot 9 \\
36 \cdot 0\end{array}\right\} 35 \cdot 9^{* *}$ \\
\hline $\begin{array}{l}\text { Duration } \\
71-70 \mathrm{~min} \\
71-90 \mathrm{~min} \\
\text { over } 90 \mathrm{~min}\end{array}$ & $\begin{array}{r}1,453 \\
418 \\
123\end{array}$ & $\begin{array}{l}1 \cdot 77 \\
1.91 \\
2 \cdot 11\end{array}$ & $\begin{array}{l}1 \cdot 21 \\
1 \cdot 28 \\
1 \cdot 50\end{array}$ & $\left.\begin{array}{l}33 \cdot 1 \\
34 \cdot 7 \\
43 \cdot 2^{*}\end{array}\right\} 33 \cdot 5^{*}$ \\
\hline $\begin{array}{l}\text { Overall opinion } \\
\text { Comfortable } \\
\text { Neither } \\
\text { Uncomfortable }\end{array}$ & $\begin{array}{l}671 \\
709 \\
614\end{array}$ & $\begin{array}{l}1 \cdot 72 \\
1.86 \\
1.87\end{array}$ & $\begin{array}{l}1 \cdot 16 \\
1 \cdot 28 \\
1 \cdot 28\end{array}$ & $\begin{array}{l}31 \cdot 7 \\
34 \cdot 9 \\
35 \cdot 5\end{array}$ \\
\hline All persons & 1,994 & $1 \cdot 82$ & $1 \cdot 24$ & $34 \cdot 0$ \\
\hline
\end{tabular}

Difference significant at $5 \%\left(^{*}\right)$ and $1 \%\left({ }^{* *}\right)$ levels (Cochran's test) 
users of private transport, the number of stages, duration of the journey, and overall opinion of the journey.

Car users had an estimated $20 \%$ more days and $17 \%$ more spells of this form of absence than persons who did not use private transport. The $6 \%$ difference in the number of persons having two or more spells is significant $(\mathbf{P}<0.05)$. This applied to both those persons using a car and public transport in different stages and those who used a car for the whole journey, but the increase was most marked in the younger men who had $38 \%$ more days off than younger men who did not use cars. Those who used other methods of private transport (cycle, moped, motor-bike, etc.) had the lowest rates of uncertified absence but this is based on a small number.

People having only one or two stages had less uncertified absence than those with more. The $6 \%$ difference in the numbers with two or more spells was highly significant $(P<0.01)$. However, any further increase in the number of stages beyond three did not seem to affect this. For stages of public transport only, the 249 persons having three or more such stages had more absence than the rest with a $10 \%$ increase in days lost.

The duration of the journey showed an effect only among those who took more than an hour and a half. Such persons had $17 \%$ more days and $22 \%$ more spells than the rest.

Overall opinion of the journey showed a slight association, but the differences were not significant. No relationships could be shown with other journey factors including loading assessments.

To assess the association of these factors after allowing for inter-association with other journey factors an analysis of variance was carried out with days of uncertified absence as the dependent variable (using a square root transformation to eliminate skewness). This showed that the use of a car remained as a highly significant factor; the number of stages and overall opinion were of borderline significance, but the duration of journey was not significant when the other three factors had been allowed for.

\section{Certified Influenza and the Journey}

The large outbreak of $A_{2}$ (Hong Kong) influenza in the course of the year enabled us to assess whether travel in crowded conditions could be shown to influence the spread of the disease.

For this analysis we used the percentage of persons with certified absence due to influenza standardized
TABLE VII

CERTIFIED INFLUENZA AND THE JOURNEY TO WORK (Annual percentage of persons certified, standardized for age, sex, and job grade)

\begin{tabular}{|c|c|c|}
\hline & $\begin{array}{l}\text { No. of } \\
\text { Persons }\end{array}$ & $\%$ with 'Flu \\
\hline $\begin{array}{l}\text { Public transport } \\
\text { Use of LT trains } \\
\text { Other public transport only } \\
\text { No public transport }\end{array}$ & $\begin{array}{r}1,010 \\
880 \\
104\end{array}$ & $\begin{array}{l}16 \cdot 5 \\
19 \cdot 3 \\
19 \cdot 0\end{array}$ \\
\hline $\begin{array}{l}\text { Overall opinion } \\
\text { Comfortable } \\
\text { Neither } \\
\text { Uncomfortable }\end{array}$ & $\begin{array}{l}671 \\
709 \\
614\end{array}$ & $\begin{array}{l}16 \cdot 4 \\
18 \cdot 6 \\
18 \cdot 8\end{array}$ \\
\hline $\begin{array}{l}\text { Crowding in LT trains } \\
\text { Load factor } 0 \text { - } \\
\begin{array}{c}50- \\
70-\end{array}\end{array}$ & $\begin{array}{r}136 \\
109 \\
54\end{array}$ & $\left.\begin{array}{l}\begin{array}{l}15 \cdot 5 \\
20 \cdot 9 \\
30 \cdot 9\end{array}\end{array}\right\} 17 \cdot 0 *$ \\
\hline $\begin{array}{c}\text { Crowding in BR trains } \\
\text { Load factor } 0- \\
70- \\
100\end{array}$ & $\begin{array}{l}101 \\
176 \\
185\end{array}$ & $\left.\begin{array}{l}22 \cdot 4 \\
21 \cdot 3 \\
13 \cdot 3\end{array}\right\} 21 \cdot 7 *$ \\
\hline All persons & 1,994 & $17 \cdot 9$ \\
\hline
\end{tabular}

- Difference significant at $5 \%$ level (Cochran's test)

for age, sex, and employment status. In Table VII this rate is shown for the sample divided according to the use of public transport, the overall opinion of the journey, and also for the loading factors for BR and LT train journeys.

As LT trains provide the most crowded form of public transport we looked at the experience of their passengers in our sample and found that they had a slightly lower rate of influenza than those who used only other public transport. Moreover, those who used no public transport at all had just as much influenza as the rest. Among the 299 persons using LT trains as their only form of transport, for those whose journey was most crowded (LT loading factor of $70 \%$ or more) the spells rate of influenza was $31 \%$ compared with $18 \%$ among those whose loading factor was less; however, there were only 54 people in the former group. A similar comparison among those using only BR trains, however, produced the paradoxical result of the higher rate of influenza among those whose loading factor was under $100 \%$.

None of the other journey factors showed any association with influenza although there was a slightly higher rate among those whose overall opinion of the journey was poor.

\section{Other Certified Absence and the Journey}

As with uncertified absence we used three measures for this analysis, spells, days, and the percentage of persons with one or more spells. In 
TABLE VIII

OTHER CERTIFIED ABSENCE AND THE JOURNEY TO WORK

(Frequency, severity, and percentage of persons with any spells, standardized for age, sex, and job grade)

\begin{tabular}{|c|c|c|c|c|}
\hline & $\begin{array}{l}\text { No. of } \\
\text { Persons }\end{array}$ & $\begin{array}{l}\text { Days } \\
\text { Rate }\end{array}$ & $\begin{array}{l}\text { Spells } \\
\text { Rate }\end{array}$ & $\begin{array}{c}\% \\
\text { Persons } \\
\text { with any } \\
\text { Spells }\end{array}$ \\
\hline $\begin{array}{l}\text { No. of stages } \\
1-3 \text { or more }\end{array}$ & $\begin{array}{r}1,577 \\
417\end{array}$ & $\begin{array}{l}4 \cdot 74 \\
6 \cdot 60\end{array}$ & $\begin{array}{l}0.46 \\
0.46\end{array}$ & $\begin{array}{l}31 \cdot 0 \\
30 \cdot 2\end{array}$ \\
\hline $\begin{array}{l}\text { Duration } \\
\text { Up to } 90 \mathrm{~min} \\
\text { Over } 90 \mathrm{~min}\end{array}$ & $\begin{array}{r}1,871 \\
123\end{array}$ & $\begin{array}{l}5 \cdot 06 \\
5 \cdot 92\end{array}$ & $\begin{array}{l}0.45 \\
0.59\end{array}$ & $\begin{array}{l}30 \cdot 6 \\
35 \cdot 7\end{array}$ \\
\hline $\begin{array}{l}\text { Private transport } \\
\text { Car } \\
\text { No private transport }\end{array}$ & $\begin{array}{r}412 \\
1,524\end{array}$ & $\begin{array}{l}4 \cdot 57 \\
5 \cdot 24\end{array}$ & $\begin{array}{l}0.39 \\
0.47\end{array}$ & $\begin{array}{l}31 \cdot 1 \\
30 \cdot 7\end{array}$ \\
\hline All persons & 1,994 & $5 \cdot 11$ & 0.46 & $30 \cdot 8$ \\
\hline
\end{tabular}

Table VIII these absence rates are shown in relation to the number of stages, the duration of the journey, and the use of a car, there being no evidence of association with other journey factors.

The most important of these was the number of stages as persons with four or more had $39 \%$ more days away than the rest. As the spells rate was not higher this means that those with four or more stages took longer absences. This tendency was confined to men and is best illustrated by the fact that $5.6 \%$ of men with four or more stages but only $3.0 \%$ of other men had 28 days or more of such absence $(\mathrm{P}<0.05)$.

The duration of the journey was of less importance, and although those with longer journeys had more spells their average length was slightly less. The use of a car was associated with slightly fewer spells of about the same length.

Analysis of variance was not done for this form of absence as the extreme skewness of its distribution, coupled with the fact that the majority of people had none, makes the use of this technique unreliable.

\section{Discussion}

This investigation had two main objectives-to assess the daily journey to work as experienced by a sample of commuters, and to assess whether their sickness absence could be related to any aspect of these journeys. It was subject to a number of limitations of method which should be considered before attempting to interpret the results.

The large number of variables known to influence rates of sickness absence made it necessary for us to select a reasonably homogeneous population, and one for which comprehensive and reliable records of all sickness absence were routinely kept. Our sample formed part of the workforce of a large organization with centres in many parts of the country. A full sick pay scheme with payment of normal wages from the first day has been in operation for a number of years, and as we considered only the office workers, these cannot be considered as representative of all workers in Central London.

The use of a self-administered questionnaire without further independent verification was necessary to preserve the anonymity of individuals. We considered that as journeys to work usually follow a set pattern, the scope for error seems small. We checked each completed form and were able to clarify the few clerical errors and inconsistencies at second hand with the individual by means of the code number. We were encouraged by the response rate and believe that the respondents took the investigation seriously. Our questions were restricted to the journey to work because we considered it would have more immediate bearing on a decision to go to work or stay at home and we were reluctant to double the size of the questionnaire and risk a greater number of refusals. It is of interest, however, that some added comments on the form that their homeward journey was more unpleasant.

The reliability of the sickness absence records should also be considered, but as the organization has an elaborate system of reporting all absence there seemed little chance of an appreciable errok of under-reporting. Allowing employees to take a? few days off work on the grounds of ill health without having to produce a medical certificate probably results in some occasions when ill health may not have been the main reason. It is relevant in this context that absence for other reasons is uncommon in this organization.

Previous studies have usually measured only the distance or time of the journey. For commuter journeys to Central London the distance itself can be of less importance as fast main line services may result in some living 30 miles away having a quicker journey than others living only 5 or 10 miles away from the office across London. A measure of the complexity of the journey was also required and for this we chose the number of stages. It could be argued that a long main line journey to a terminal near the office, which might take the same time as a more complicated journey involving bus, train, underground, and a walk, might be less likely to encourage an employee to stay at home. The association between duration and the number of stages was positive but not particularly close, and it seems that these are very different measures of a journey.

The interpretation of an individual's opinion about the comfort of the journey as a whole is difficult. Some are more likely to complain than 
others, and we found this in younger employees. Furthermore, people who complain may well be those more likely to go sick. It is of some interest that more assessed their journey as comfortable than as uncomfortable, although some of the latter felt so strongly that they chose to add explanatory notes on their forms. The lack of any strong association between subjective and objective assessments of crowding on train journeys may be because the loading factors were measured at or near the station at which the passenger left the train.

The relationships we were able to show between some factors of the journey and sickness absence raise a number of important points. Uncertified absence accounted for $21 \%$ of all sickness days recorded. This high proportion reflects the liberal policy of the organization, and it was this type of absence that showed most of the positive associations with journey factors. The bulk of sickness absence, however, was covered by a medical certificate. The fact that the number of stages was related to both certified and uncertified absence suggests that this is the most important factor. Combining all types of absence and allowing for age, sex, marital status, and job grade by indirect standardization, those whose journeys involved up to three stages had $8 \cdot 17$ calendar days per person in the year. Those with four or more stages had 9.75 days, a $19 \%$ increase. The fact that the latter group contained a higher proportion of men with four weeks or more of certified absence (excluding influenza) is perhaps an indication that those who are off sick with more serious conditions may extend their absence if they face a more complicated journey.

The total duration of the journey showed some association with absence but this was less important than the number of stages. It was only significant with uncertified absence and when the time exceeded one and a half hours.

The situation for people using a car for part or all of the journey is curious. They had significantly more uncertified absence, but their certified sickness was slightly below average in both frequency and severity. This makes it unlikely that they included a disproportionate number with chronic conditions, particularly as the use of a car was more common in younger men. While some people may use a car because it is the only means of getting from home to the station, others may use it to make their journey more comfortable than it would be by public transport. While it is possible that such people are more sensitive to minor ailments causing the odd day off, it could also be a convenient excuse for an absence when the car breaks down. The importance of behavioural aspects of sickness absence is now well recognized (Office of Health Economics, 1971), but the arrangements for this investigation did not enable us to include measures of job satisfaction.

Our failure to demonstrate any association between the use of public transport and sickness absence carries some important implications, particularly in regard to influenza. Respiratory conditions including bronchitis are always the commonest single cause of certified sickness absence in Britain (Department of Health and Social Security, 1971). It is generally accepted that transmission of the infectious group of such conditions is by droplet. The attack rate of certified influenza among our sample was comparable with that for the whole country (Miller, Pereira, and Clarke, 1971). Our failure to demonstrate higher rates among those who used public transport came as a surprise. One might have supposed that the close proximity of passengers in crowded LT underground or BR surface trains would facilitate such transmission. Perhaps the period of time for which our respondents were exposed each day was too short, perhaps the propaganda such as ...'Coughs and sneezes spread diseases, trap the germs in your handkerchief' has had a lasting effect; perhaps the habitual silence of the commuter reduces transmission, or perhaps there are other factors not allowed for in this investigation which would account for our findings.

In conclusion, this study has demonstrated the problems that arise when associations are sought between two complex phenomena. While there appears to be no dramatic association between the journey to work and sickness absence in our selected sample, the complexity of the journey proved to be the most important of the factors we studied. It may be that those whose health or morale was affected by a difficult journey had already taken steps to obviate this by changing their job or by moving house.

\section{SUMMARY}

The relationship between the pattern of commuter travel to work and sickness absence has been studied in a population of 1,994 office workers in Central London.

The median time for the whole journey was one hour and the average journey had $2 \cdot 8$ stages. Onethird of the sample considered their journey to be uncomfortable. The number of stages of the journey was the most important factor to relate to both certified and uncertified sickness absence. The use of a car or a journey lasting over one and a half hours was associated with higher uncertified rates 
of absence. The incidence of certified influenza did not relate to any aspect of the journey including the use of public transport.

We are extremely grateful to all our respondents and to those members of the organization's personnel department who assisted us in the collection of the information. We are also most grateful to British Rail and the Department of the Environment for supporting this investigation and to BR and LT staff who assisted us by providing loading factors.

Copies of the questionnaire will be provided on request.

\section{REFERENCES}

Buzzard, R. B., and LidDell, F. D. K. (1963). Coalminers attendance at work. Medical Research Memorandum 3. National Coal Board Medical Service.

Department of Health and Social Security (1971). Annual Report 1970. Cmnd. 4714. H.M.S.O., London.

FrogGatT, P. (1970). Short-term absence from industry. Brit J. industr. Med., 27, 199.

JONES, R. M. (1971). Absenteeism. Department of Employment, Manpower Papers No. 4. H.M.S.O., London.
LIEPMANN, KATE, K. (1944). The Journey to Work, its Significance for Industrial and Community Life. Kegan Paul, Trench, Trubner and Co., London.

Miller, D. L., Pereira, M. S., and Clarke, M. (1971). Epidemiology of the Hong Kong/68 variant of influenza $A_{2}$ in Britain. Brit. med. J., 1, 475.

Norman, L. G. (1959). The health of London's travelling public. Roy. Soc. Hlth J., 79, 229.

Office of Health Economics (1971). Off Sick, O.H.E. Publications, No. 36.

TAYLOR, P. J. (1966). M.D. thesis, pp. 70 and 88, University of London.

VerNon, H. M., BEDFord, T., and WARNER, C. G. (1931). Two Studies of Absenteeism in Coal Mines. Rep. Industr. Hlth Res. Bd (Lond.), No. 62. H.M.S.O., London.

Williams, R. E. O., and Hirch, ANN (1950). Bacterial contamination of air in underground trains. Lancet, $1,128$.

WyatT, S., Marriott, R., and Hughes, D. E. R. (1943). A Study of Absenteeism among Women. Rep. industr. Hlth Res. Bd(Lond.), Emergency Report No. 4. H.M.S.O., London. 